\title{
Focus on Increasing Exposure to Surgery Instead of on Creating Role Models
}

\author{
Adam M. Ali
}

Published online: 26 April 2011

(C) Société Internationale de Chirurgie 2011

Ravindra and Fitzgerald report that the junior doctors they interviewed were more likely to express an interest in pursuing a surgical career if they could identify a positive "surgical role model" [1]. However, there is likely to be a large amount of recall bias in this study in that doctors wishing to study surgery are more likely to remember potential role models.

The causation is not that the presence of such figures creates interest in surgery but that many medical students are interested in surgery already and then seek out inspirational surgeons for further guidance [2]. In a large teaching hospital such as the Queen's Medical Centre in Nottingham (where the junior doctors in the trial were trained), a surgeon who is a "positive role model" would be easy enough to find among the large number of surgeons working there should a student so desire.

The conclusion that the drive to increase interest in surgery should be focused on increasing the number of surgical role models is thus flawed. The focus should, instead, be on enabling as much student exposure to surgery as possible in the medical school curricula [3], with the realistic expectation that at least some surgeons in teaching hospitals will take interested students under their wing without having to be told to do so.

\section{References}

1. Ravindra P, Fitzgerald JEF (2011) Defining surgical role models and their influence on career choice. World J Surg 35:704-709. doi:10.1007/s00268-011-0983-0

2. Erzurum VZ, Obermeyer RJ, Fecher A et al (2000) What influences medical students' choice of surgical careers. Surgery 128:253-256

3. O'Herrin JK, Lewis BJ, Rikkers LF et al (2004) Why do students choose careers in surgery? J Surg Res 119:124-129

\footnotetext{
A. M. Ali $(\bowtie)$

Green-Templeton College, Woodstock Road,

Oxford OX26HG, UK

e-mail: adamali@post.harvard.edu
} 